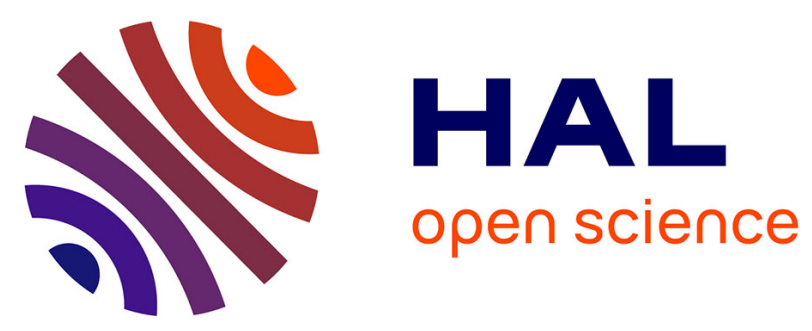

\title{
Resonance measurements techniques of optical whispering gallery mode mini-disc resonators for microwave photonics applications
}

P. Salzenstein, M. Jelinek, Y.K. Chembo, M. Pogurmirskiy, H. Tavernier, K. Volyanskiy, K. Phan Huy, M. Chauvet, L. Larger, V. Kubecek

\section{To cite this version:}

P. Salzenstein, M. Jelinek, Y.K. Chembo, M. Pogurmirskiy, H. Tavernier, et al.. Resonance measurements techniques of optical whispering gallery mode mini-disc resonators for microwave photonics applications. Conference on Nonlinear Optics and Applications V, Apr 2011, Prague, Czech Republic. pp.807104, 10.1117/12.886380 . hal-00655137

\section{HAL Id: hal-00655137 https://hal.science/hal-00655137}

Submitted on 19 Apr 2021

HAL is a multi-disciplinary open access archive for the deposit and dissemination of scientific research documents, whether they are published or not. The documents may come from teaching and research institutions in France or abroad, or from public or private research centers.
L'archive ouverte pluridisciplinaire HAL, est destinée au dépôt et à la diffusion de documents scientifiques de niveau recherche, publiés ou non, émanant des établissements d'enseignement et de recherche français ou étrangers, des laboratoires publics ou privés. 


\title{
Resonance measurements techniques of optical whispering gallery mode mini-disc resonators for microwave photonics applications
}

\author{
Patrice Salzenstein*ª , Michal Jelínek ${ }^{\mathrm{b}}$, Yanne K. Chembo ${ }^{\mathrm{a}}$, Maxim Pogurmiskiy ${ }^{\mathrm{c}}$, Hervé Tavernier ${ }^{\mathrm{a}}$, \\ Kirill Volyanskiy ${ }^{a}$, Kien Phan Huy ${ }^{a}$, Mathieu Chauvet ${ }^{a}$, Laurent Larger ${ }^{a}$ and Václav Kubeček ${ }^{b}$ \\ anstitut Franche Comté Electronique Thermique Optique - Sciences et Technologie (FEMTO-ST), \\ Centre National de la Recherche Scientifique (CNRS), 26 Chemin de l'épitaphe, F25000 Besançon, \\ France \\ ${ }^{\mathrm{b}}$ Czech technical university in Prague, Faculty of Nuclear Sciences and Physical Engineering, Czech \\ republic \\ ${ }^{c}$ National Research University of Information Technology Mechanics and Optics (ITMO) Saint- \\ Petersburg, Russia
}

\begin{abstract}
The aim of this work is to compare advantages and disadvantages of different techniques for coupling a mini-discoptical-resonator to determine quality factor of its resonance. Optical fiber coupled to a resonator consists in a mini disc with whispering gallery modes at its circumference. We choose to work with three materials and design compact miniresonators. Fused silica is found to be suitable for these applications thanks to its hardness in the range 6-7 and the behavior to mechanical shocks, despite its sensitivity to water pollution. With its tetragonal crystal and a good behavior with risk of water pollution, Calcium fluoride is a good candidate despite sensitivity to mechanical shocks. Magnesium fluoride is the third material used. As a critical step, taper coupling is set with a $20 \mathrm{~nm}$ resolution positioning system. Miniresonator is excited from a system equipped with a tunable laser diode with a tunability from 1490 to $1640 \mathrm{~nm}$ and a linewidth narrower than $300 \mathrm{kHz}$. Light is coupled into the microsphere either from glass or fiber prism or with fiber taper via evanescent field. We have also used a single frequency $660 \mathrm{~nm}$ laser diode with a linewidth narrower than $100 \mathrm{kHz}$ which can be tuned about $10 \mathrm{pm}$ to test a single resonant peak. Both sources are used with either a tapered fiber or a filed fiber. Resonance is observed and quality factor of the resonators is found to be in the range of $10^{8}$.
\end{abstract}

Keywords: Optoelectronic, optical coupling, optical resonator, $\mathrm{CaF}_{2}, \mathrm{MgF}_{2}$, Fused silica

\section{INTRODUCTION}

Optical resonators present interest to make optoelectronic oscillators and it can consist in either optical fiber delay lines, spherical or disc resonators [1-4]. In this paper are presented some methods used for coupling from optical fiber to optical mini-resonators and resonance measurement technique. Although the aim of this work is to compare different techniques for coupling mini-resonators, we focus on tapered fiber realized in Prague or Besançon and describe limitation and results of these techniques, by presenting early results of this collaboration between both laboratories.

\section{COUPLING PROCESS AT FEMTO-ST}

Two optical disc resonators made from Fused silica and $\mathrm{MgF}_{2}$ were used for experiments. Their diameter is in the range of $5 \mathrm{~mm}$ corresponding to a Free Spectral Range (FSR) in X-band around $10 \mathrm{GHz}$ for $1.55 \mu \mathrm{m}$ wavelenght. Despite the best way to couple the fiber to an optical resonator certainly consists in using a prism with a signal provided by a cut optical fiber, it was decided to use a tapered fiber method because of the smaller foot-print and of a the better coupling reproducibility. Taper is drawn with a step-by-step motor computer controlled. One can note that it is better to proceed

* Corresponding author patrice.salzenstein@ femto-st.fr; phone +33 381402849 
with a symmetrical system using two motors. While fiber is heated and elongated transmission is monitored. Fig. 1 represents a view of the fiber being filed.

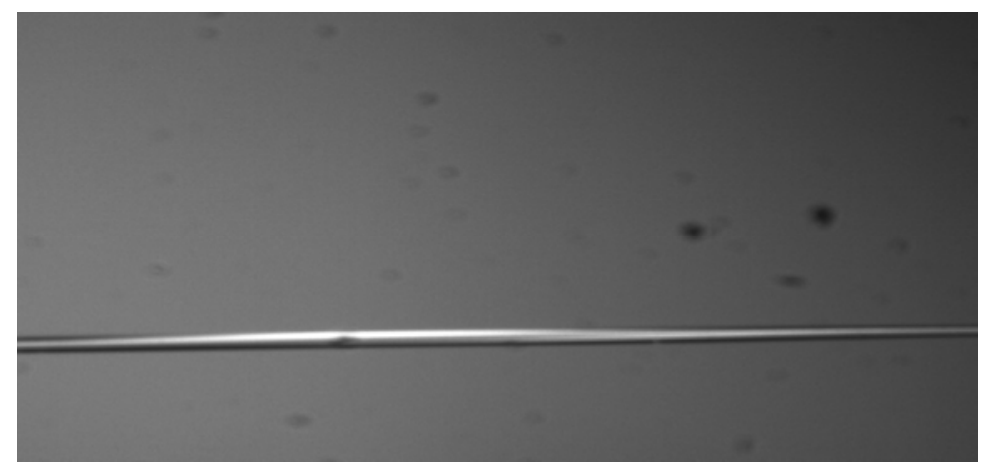

(a)

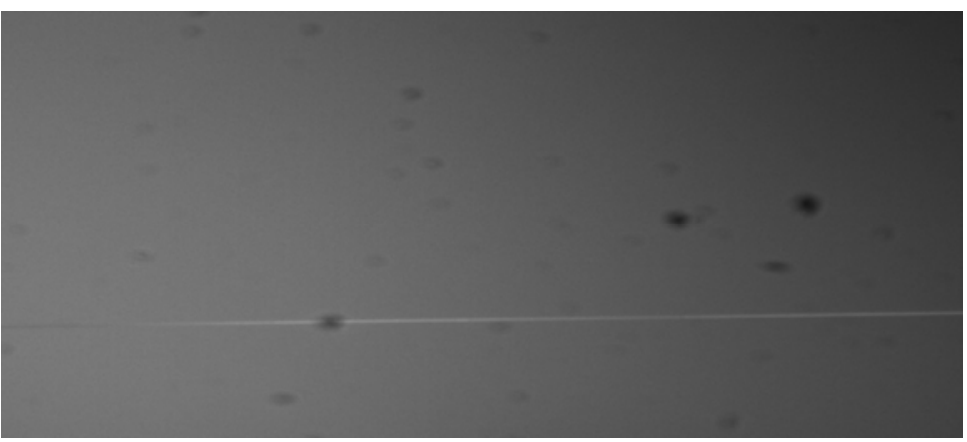

(b)

Figure 1. Manufacturing of the taperered fiber. (a) and (b) respectively before and after fabrication.

Fiber is then fixed on a holder. On the taper, holder alloy and geometry match the thermal expansion of the glass. We proceed identically with resonators manufactured in our laboratory or in Saint-Petersburg [5]. In Fig. 2, we can see how the taper is positioned by a nano-positioning system in order to find the resonance modes and characterize the resonator coupled to the fiber [6].

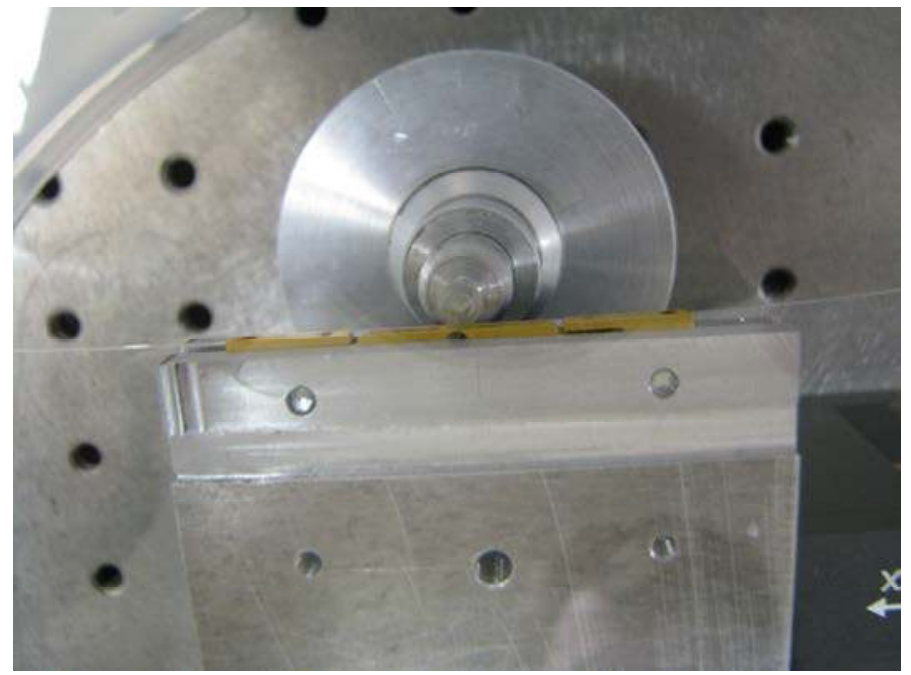

Figure 2. Picture of the set-up to couple the light from the fiber to the disc. 


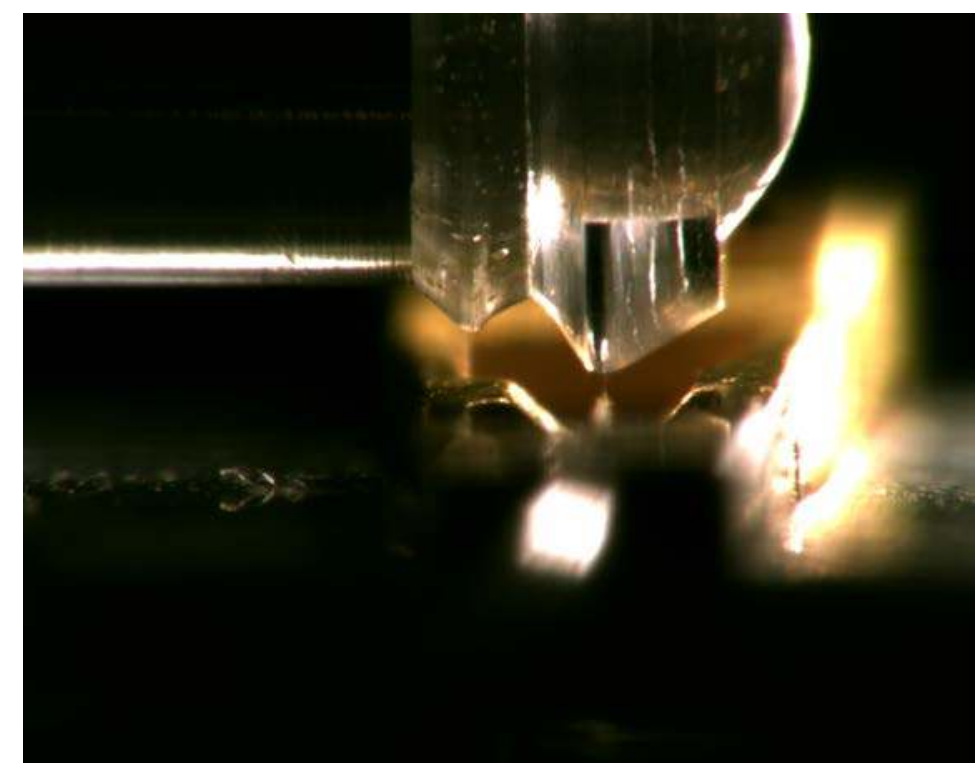

(a)

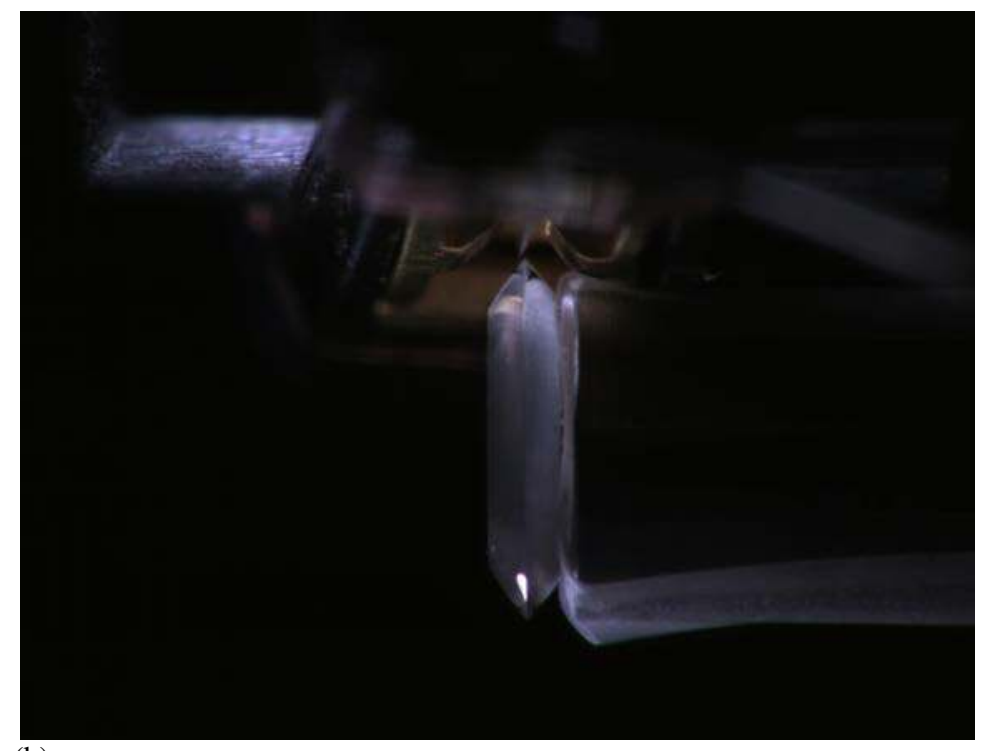

(b)

Figure 3. Coupling to the fiber.

Coupling the fiber to this resonator is not obvious because of the difficulty of the alignment. Fig. 3 shows a side view during critical step of coupling the resonator to the optical fiber. (a) and (b) shows two kind of resonators, Magnesium fluoride of Fused silica based with two different holders.

In order to characterize the resonance, a signal from a $1550 \mathrm{~nm}$ tunable laser diode has been used. Fast digital real time 8600A-type Lecroy oscilloscope provides an analysis of the very sharp phenomena at the peak of resonance. It is necessary to use a high speed resolution oscilloscope, because we need to analyze very fast phenomena. An oscilloscope is connected to a photodiode that detects an optical signal, which is coming from the mini-disc resonator coupled to the fiber glued on the holder. The resonance peak detection corresponds to a single mode excitation. A small taper size is helpful to select a thin excitation area. 


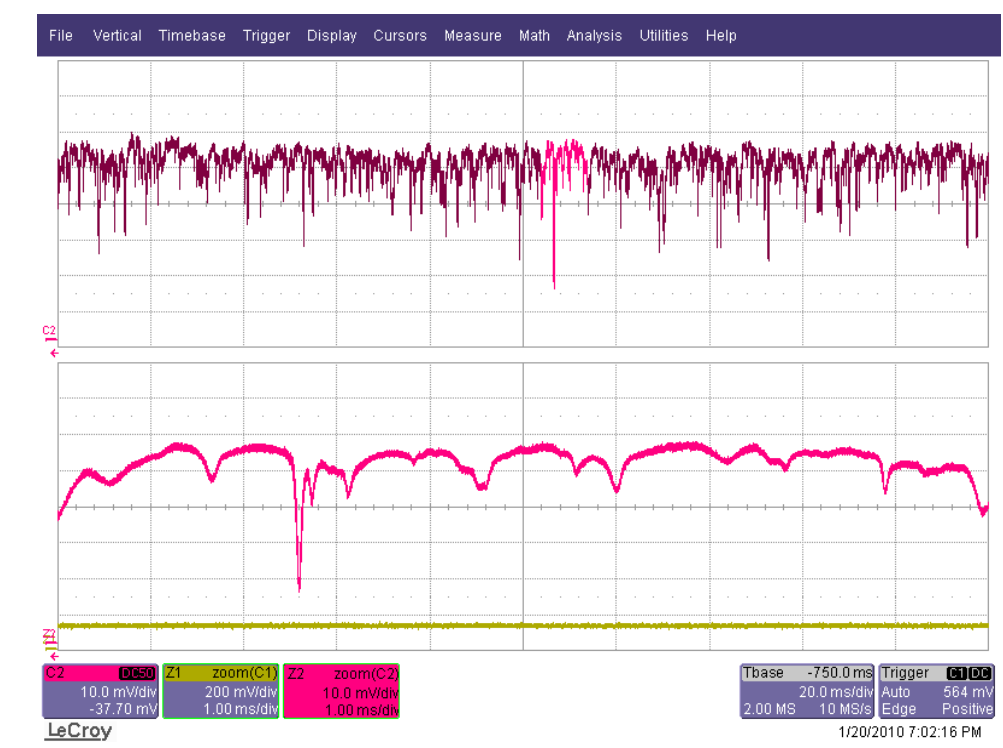

Figure 4. $\mathrm{Q}=8 \cdot 10^{7}$.measured on a fused silica resonator.

Fig. 4 presents the modes measured on Fused silica mini-resonator. The resonance measurement set-up is in open loop. The corresponding $\mathrm{Q}$ factor is in the range of $8.10^{7}$. Then coupled resonator is included into an oscillator and provides microwave oscillations stabilized to the resonator free spectral range, in the X-band region as predicted by the FSR. The delivered power is higher than $1 \mathrm{dBm}[7,8]$. Such power is enough to allow characterization by optoelectronic phase noise measurements systems [9].

\section{COUPLING PROCESS AT THE CZECH TECHNICAL UNIVERSITY}

According means developed in the laboratory for micro-spheres [10], two optical disc resonators made from Fused silica and $\mathrm{CaF} 2$ were used for experiments. The $\mathrm{CaF} 2$ disc diameter is $5,5 \mathrm{~mm}$ and corresponds to a $\sim 12,2 \mathrm{GHz}(100 \mathrm{pm} @$ $1565 \mathrm{~nm}$ ) Free Spectral Range (FSR). The Fused Silica disc diameter is $5 \mathrm{~mm}$ and corresponds to a $\sim 13 \mathrm{GHz}\left(10^{8} \mathrm{pm} @\right.$ $1565 \mathrm{~nm})$ FSR.

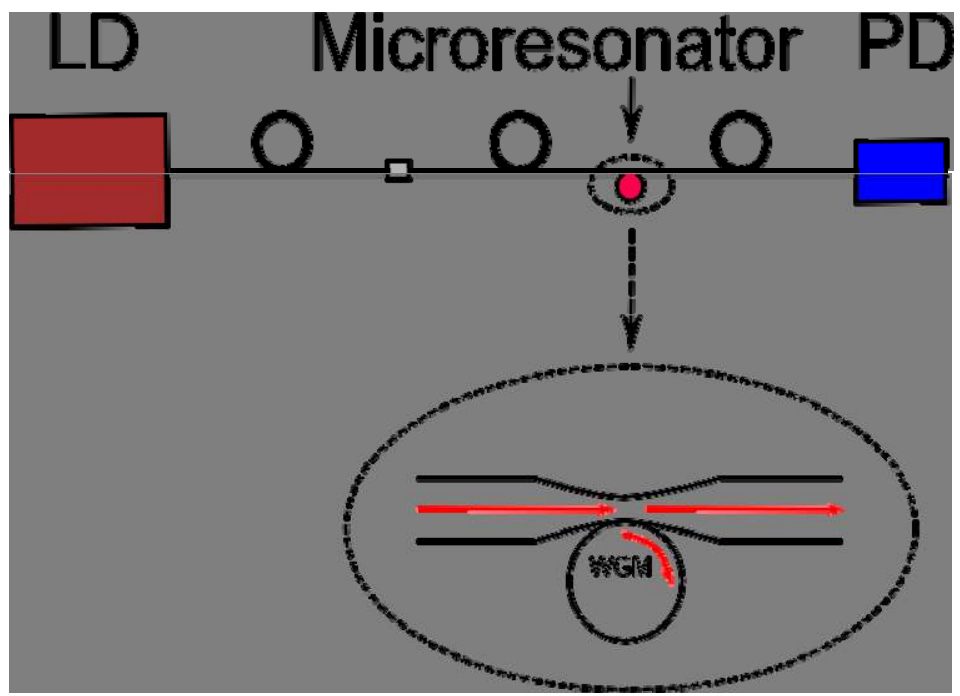

Figure 5. WGM excitation in the disc - experimental setup. 
WGM modes were excited by the fiber taper. The experimental setup is schematically shown on figure 5. As a laser source, the DFB telecommunication diode working at the central wavelength of $1565 \mathrm{~nm}$ and line-width of $3 \mathrm{MHz}$ was used. Output wavelength was tuned by current change and maximal tuning range of $\sim 1 \mathrm{~nm}$ was calibrated. Transmitted light through the fiber was measured by a photodiode Thorlabs FGA04 connected to the oscilloscope. The disc was aligned as precisely as possible using red laser diode connected to the taper. Photographs of the aligned disc are shown on fig. 6. Red light around the disc was observed due to weak light scattering.

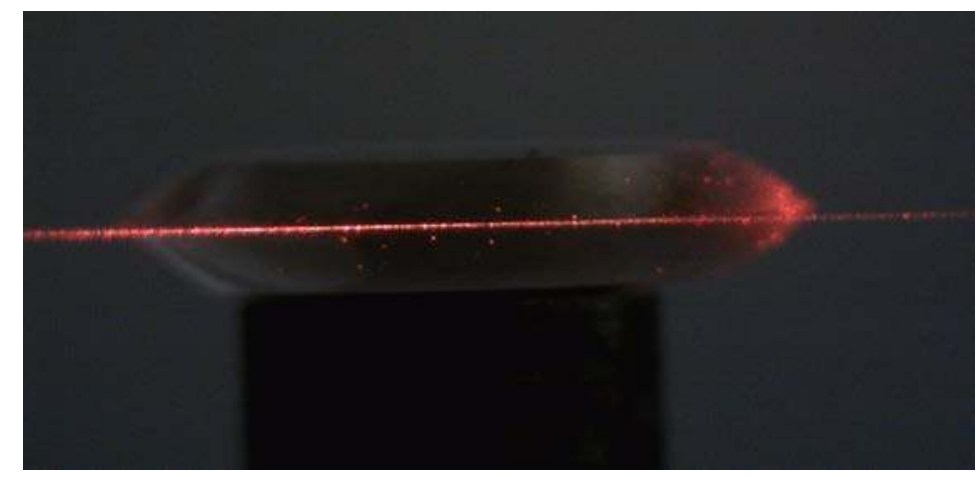

(a) side view

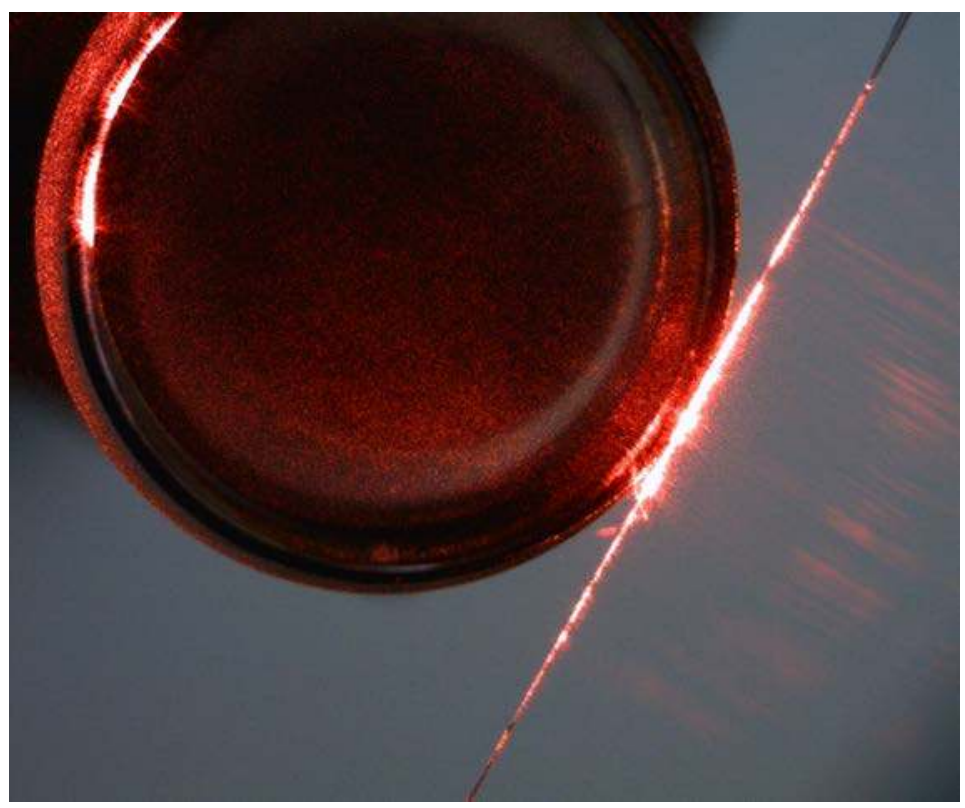

(b) top view

Figure 6. The disc during alignment illuminated by the red laser diode.

For the measurement a new taper (label Filip22Mar2011) was used. During the manufacturing process, a small ring (D $2 \mathrm{~mm}$ ) accidentally appeared. This ring is clearly seen in Fig. 7 and Fig. 8. The disc was aligned as precisely as possible using red laser diode connected to the taper. Photographs of the aligned disc are shown in Fig. 7 (FS disc) and Fig. 8 $\left(\mathrm{CaF}_{2}\right.$ disc). Red light around the disc was observed, but its origin is not exactly known. The red diode is quite "largebandwidth", but probably the red light is just some scattering effect. After the precise alignment was prepared, the tunable laser diode was coupled into the fiber. When the disc was put into the contact with the taper, transmitted power drop in the order of magnitude was observed. In the transmitted power some resonance "dips" or "peaks" appear, as is described in the following sections. 


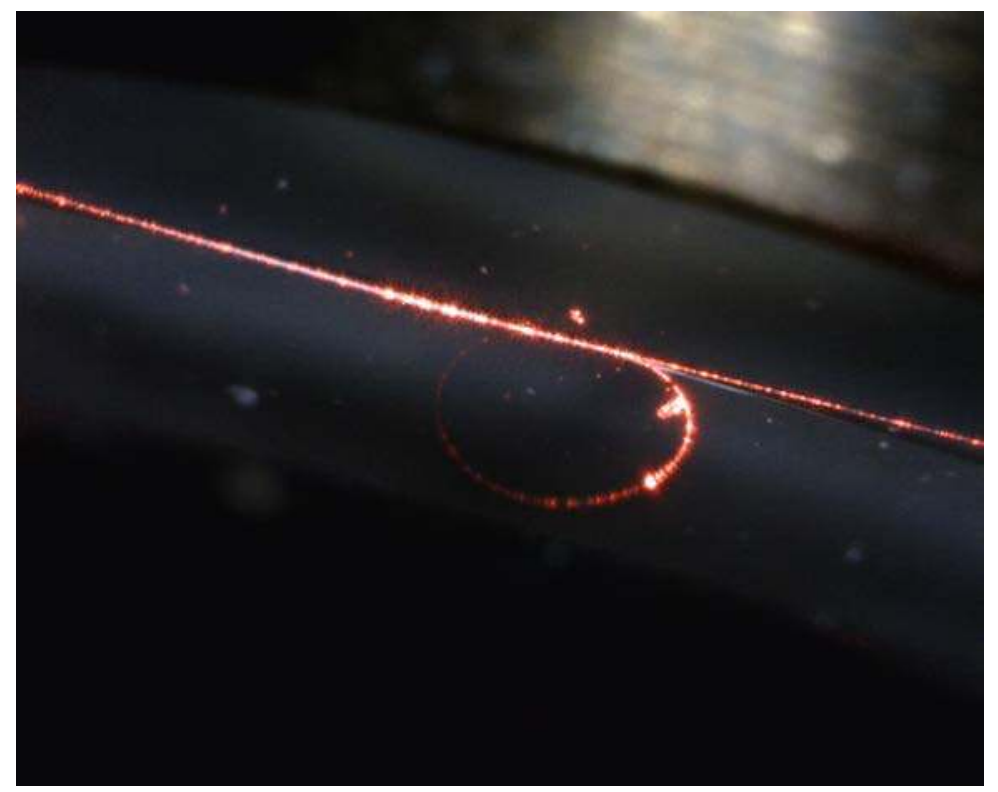

Figure 7. FS disc during the alignment.

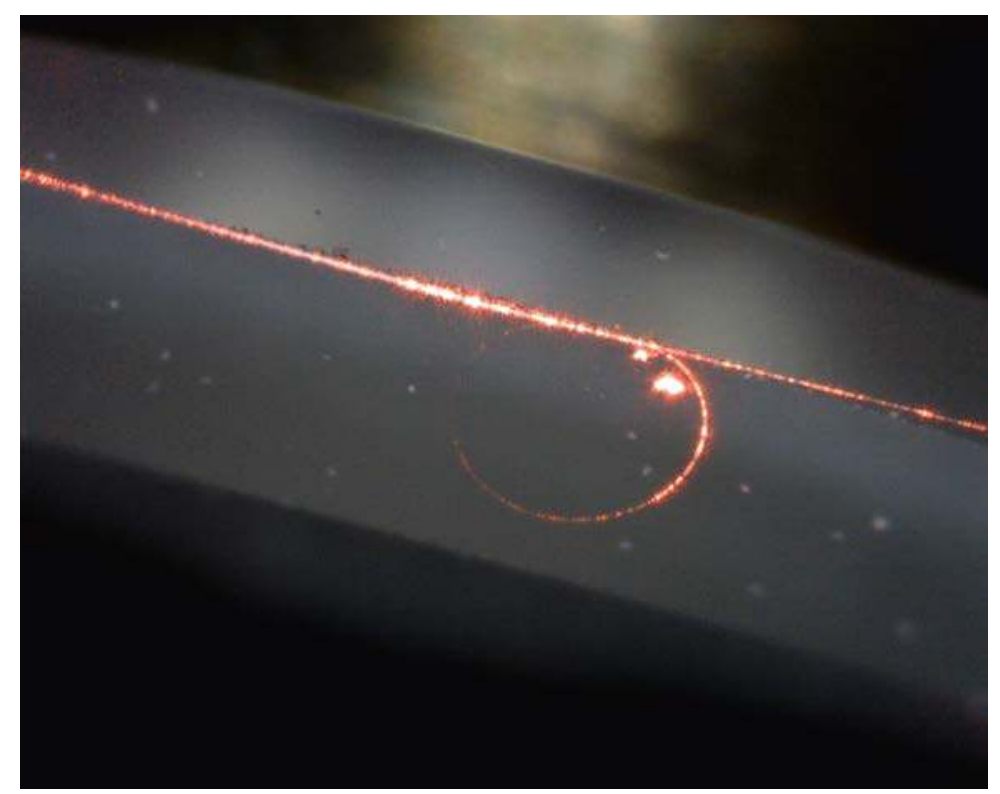

Figure 8. $\mathrm{CaF}_{2}$ disc during the alignment.

\subsection{FS disc :}

Example of the recorded oscillogram of the transmitted power is shown in Fig. 9. When the disc was not in the contact with the taper, no such modulation was observed. In the figure can be seen the peaks, whose distance corresponds to the disc FSR. Around $60 \mathrm{GHz}$ and lower the distance is little bit larger, which can be explained by the fact that the laser diode output wavelength is tuned by the current and at lower current values its dependence may not be strictly linear.

There is still a question why the peaks are observed instead of the expected dips. The situation may be interpreted as most of the power is coupled into the disc and just the resonance modes are coupled back into the fiber, but we are really not sure about this. 


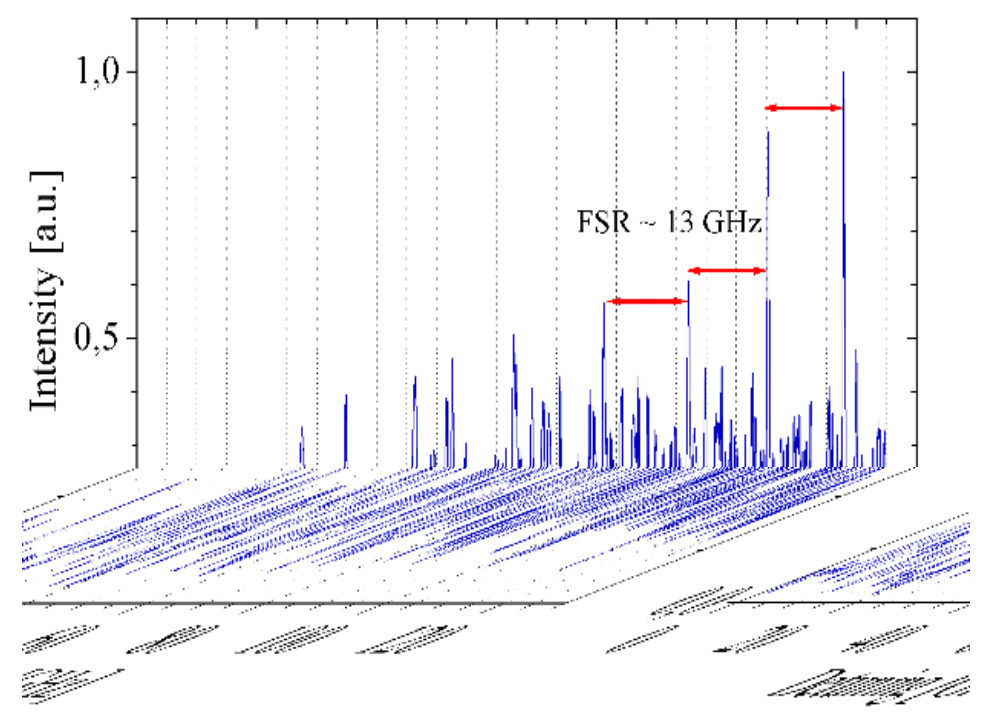

Figure 9. FS disc - transmitted power during output wavelength tuning (Tek24).

Detail of two (highest) peaks from Fig. 9 is shown in Fig. 10, one single peak is shown in Fig. 11. The peak width is 350 $\mathrm{MHz}$ corresponding to $\mathrm{Q}$ factor of $5.5 \times 10^{5}$.

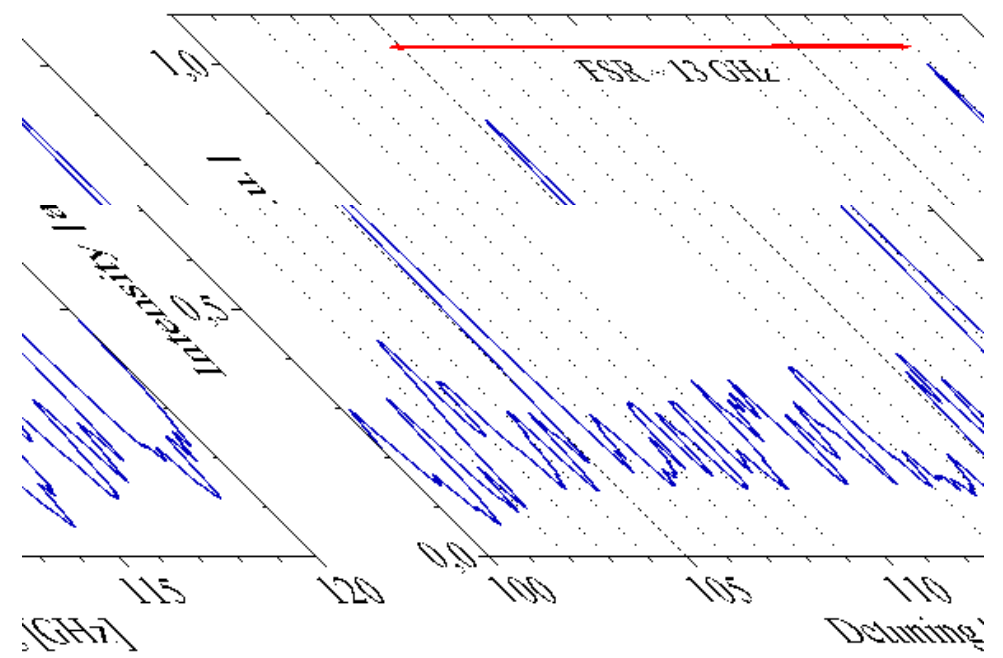

Figure 10. FS disc: detail of two peaks (Tek24).

In the next experiments the laser diode output wavelength was tuned by the temperature (using temperature controller in the range about $10^{\circ} \mathrm{C}$ ). Repeatable shift in the spectrum was observed. 


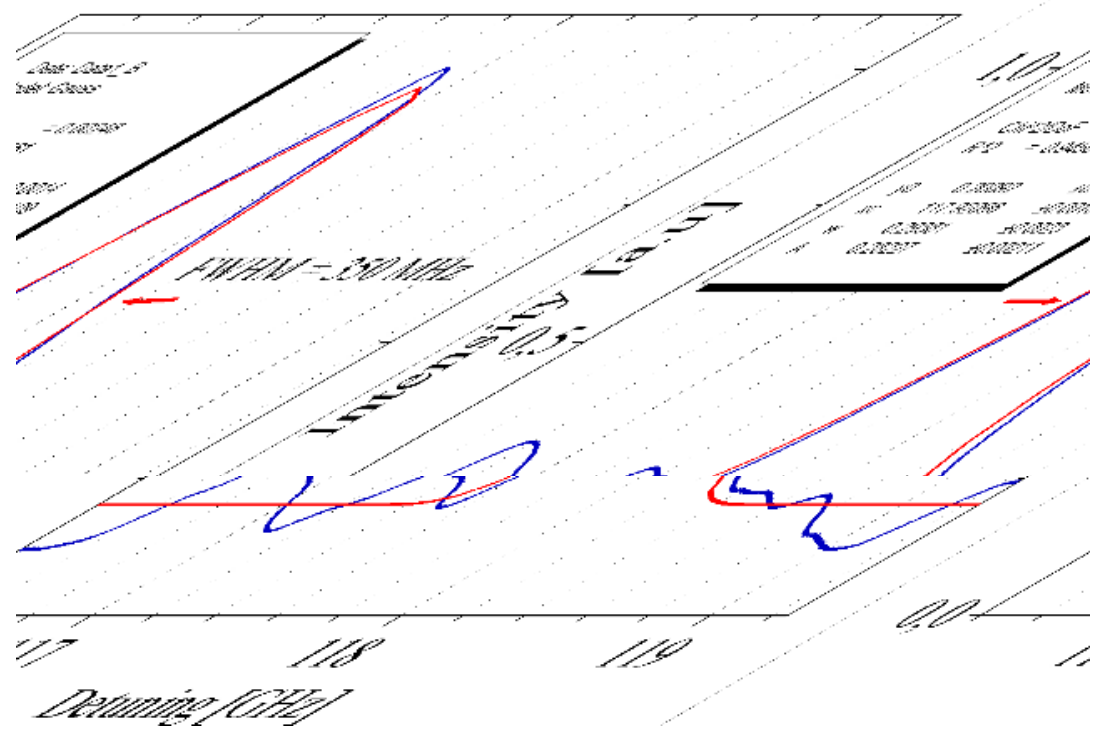

Figure 11. FS disc: detail of one single peak (Tek24).

In Fig. 12, Fig. 13, and Fig. 14 are shown examples of several other tuning spectrums obtained by the alignment change of the disc and the taper.

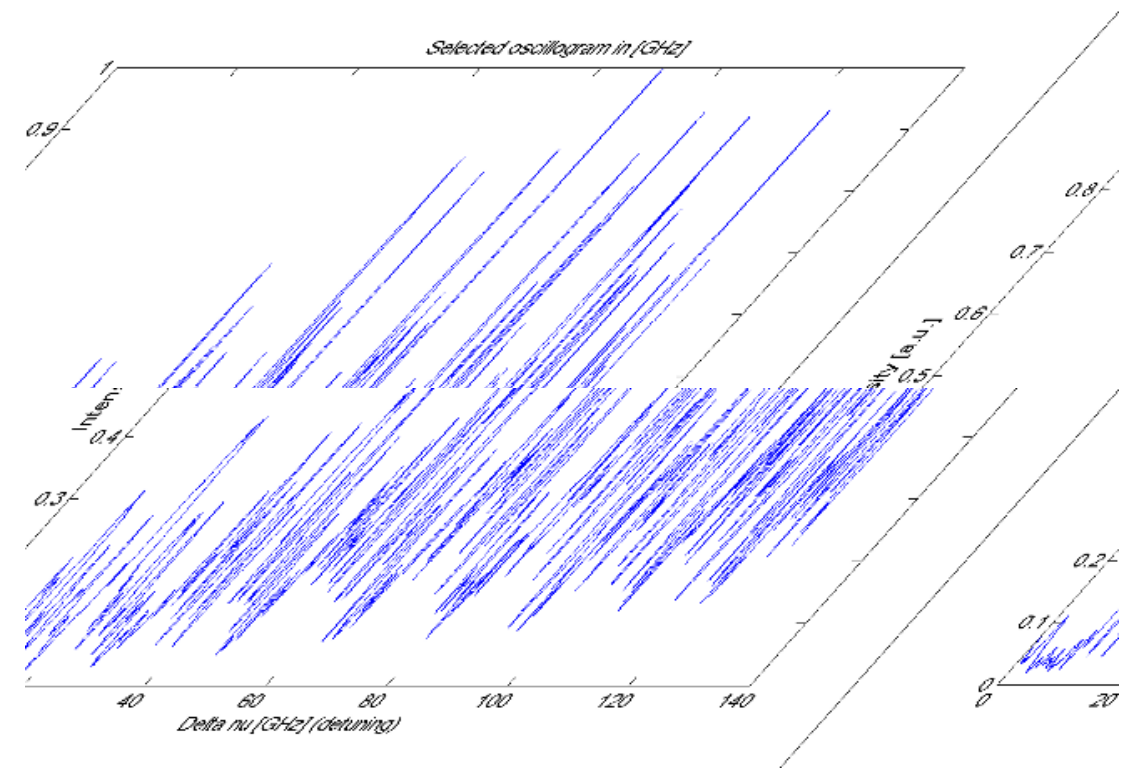

Figure 12. FS disc-example n.1 of transmitted power during output wavelength tuning (Tek28). 


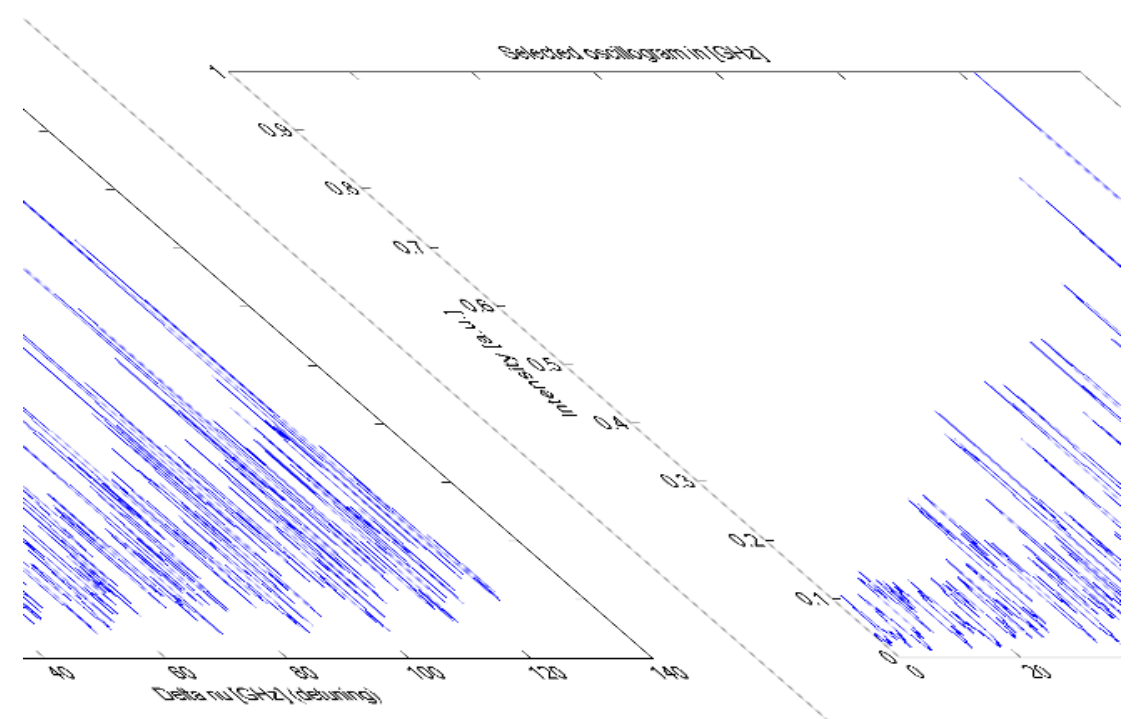

Figure 13. FS disc - example n.2 of transmitted power during output wavelength tuning (Tek32).

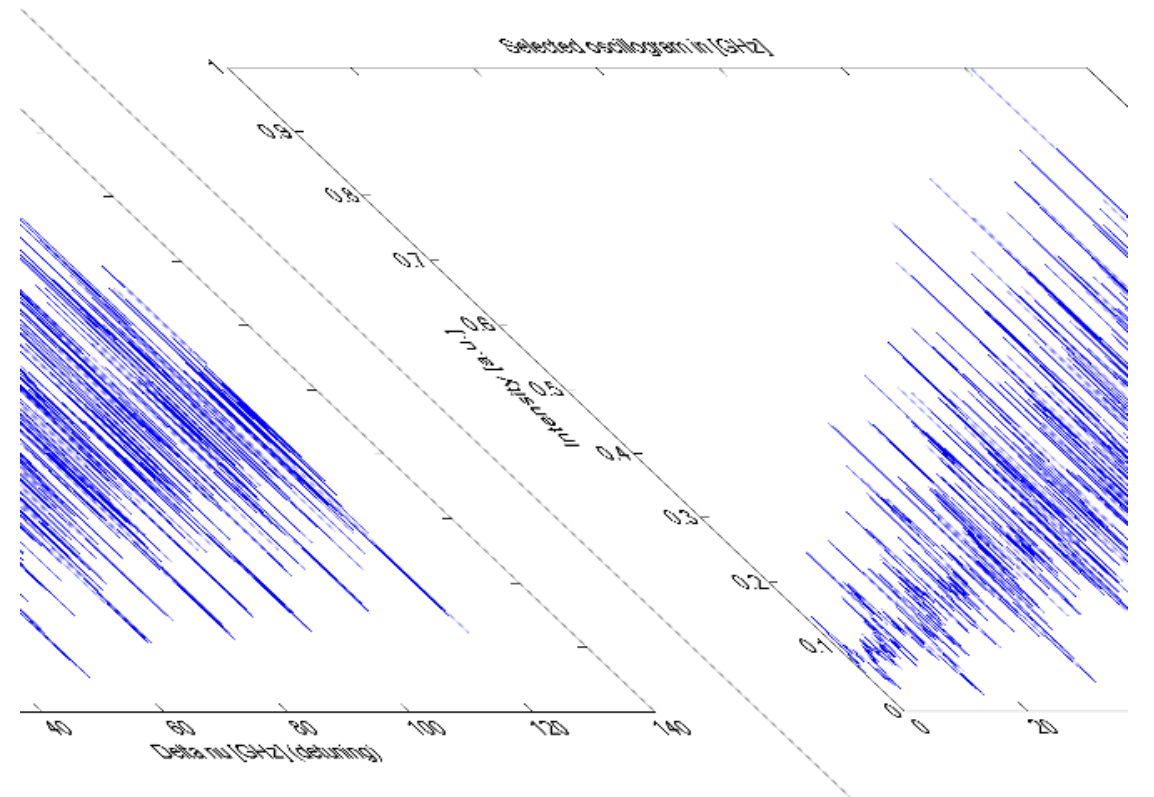

Figure 14. FS disc - example n.3 of transmitted power during output wavelength tuning (Tek43).

\section{2. $\mathrm{CaF}_{2}$ disc :}

Example of the recorded oscillogram of the transmitted power using $\mathrm{CaF}_{2}$ disc is shown in Fig. 15. Like in the case of FS disc, the peaks corresponding to FSR can be seen. 


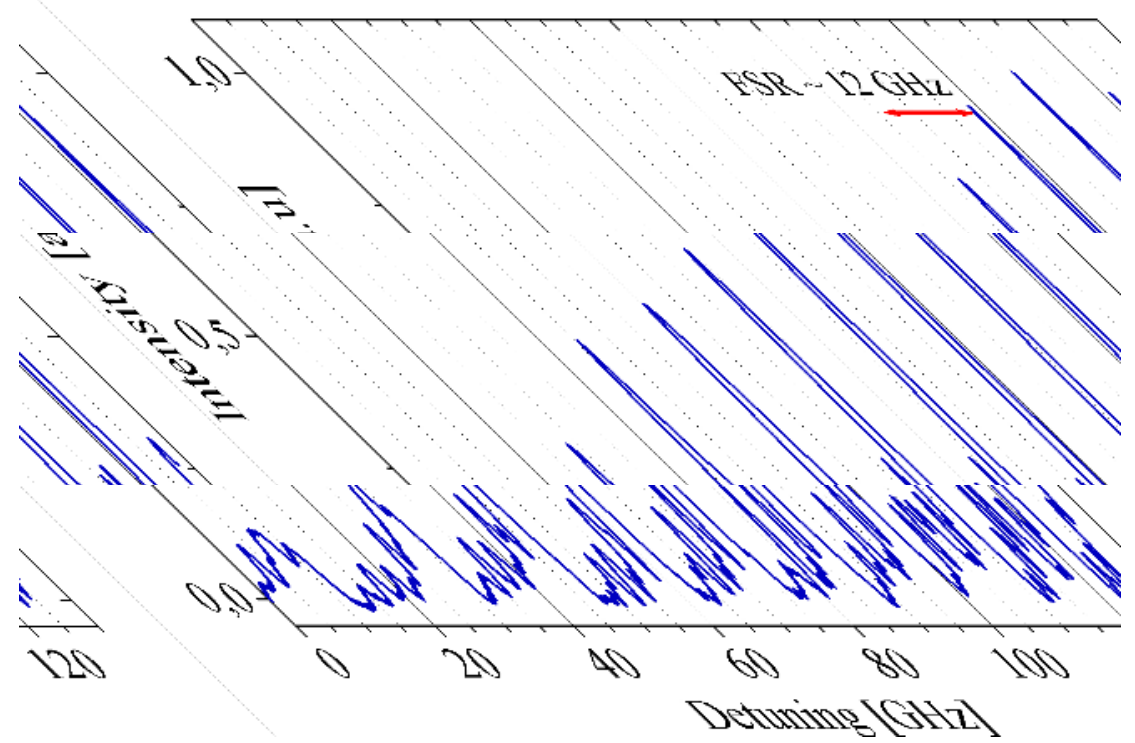

Figure 15. FS disc - example n.3 of transmitted power during output wavelength tuning (Tek43).

In Fig. 16 the detail of one peak is shown. The peak width is $1 \mathrm{GHz}$ corresponding to $\mathrm{Q}$ factor of $2 \times 10^{5}$.

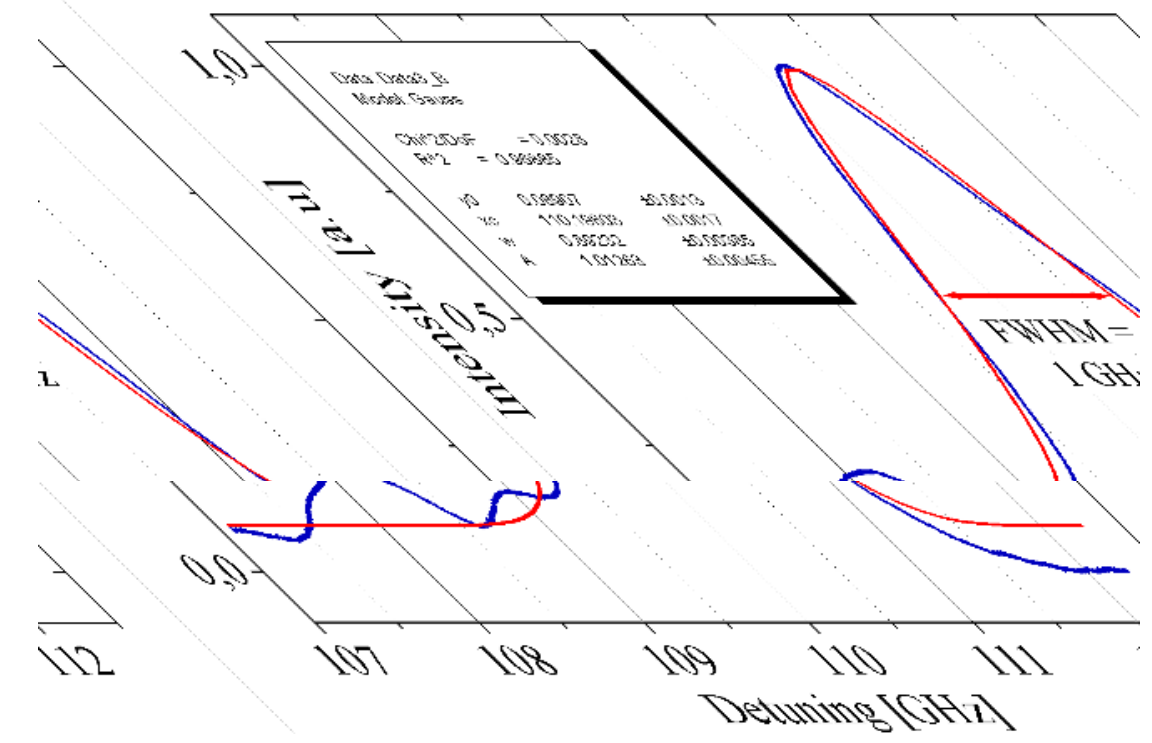

Figure 16. $\mathrm{CaF}_{2}$ disc: detail of one single peak (Tek13).

Like in the case of FS disc, the laser diode output wavelength was tuned by the temperature (using temperature controller in the range about $10^{\circ} \mathrm{C}$ ) and repeatable shift in the spectrum was observed. Similar spectrum was measured several times and according to the alignment, less or more peaks appear.

\section{FIRST CONCLUSIONS}

Two tapers were fabricated in Besançon, leading to first promising results for high quality factors resonators and microwaves optoelectronic oscillators. Two resonators were then also characterized in Prague. Four tapers and many experiments were performed there, but the very early results are still not as good as expected. Modulations of the tuned transmitted laser light were observed, and, resonance was found with the corresponding microwave FSR was observed. 


\section{ACKNOWLEDGEMENTS}

This work was partly supported in France by the Agence National de la Recherche (ANR) under contract number ANR2010-BLAN-0312-02.

\section{REFERENCES}

[1] I. S. Grudinin, V. S. Ilchenko, and L. Maleki, "Ultrahigh optical Q factors of crystalline resonators in the linear regime,"Phys. Rev. A, 74(6), 063806(9) (2006)

[2] Yao X. S. and Maleki L., "High frequency optical subcarrier generator," Electronics Letters, 30(18), 1525-1526 (1994).

[3] Ilchenko V. S., Yao X. S. and Maleki L., "High-Q microsphere cavity for laser stabilization and optoelectronic microwave oscillator," Proc. SPIE, 3611, 190-198 (1999).

[4] Schliesser A and Kippenberg T. J., "Cavity Optomechanics with Whispering-Gallery Mode Optical MicroResonators," Acta Avances in Atomic Molecular and Optical Physica, 58, 207-323 (2010).

[5] Salzenstein P., Volyanskiy K., Rubiola E. and Larger L., "Compact optoelectronics oscillators using WGM modes on fused silica and MgF2 mini-disks resonators," Proc. of SPIE, 7716, 77162C (2010).

[6] Tavernier H., Salzenstein P., Volyanskiy K., Chembo Y. K. and Larger L., "Magnesium Fluoride Whispering Gallery Mode disk-Resonators for Microwave Photonics Applications," IEEE Photonics Technology Letters, 22(22), 1629-1631 (2010).

[7] Salzenstein P., Tavernier H., Volyanskiy K., Kim N. N. T., Larger L. and Rubiola E., "Optical mini-disk resonator integrated into a compact optoelectronic oscillator," Acta Physica Polonica A, 116(4), 661-663 (2009).

[8] Volyanskiy K., Salzenstein P., Tavernier H., Pogurmirskiy M., Chembo Y. K. and Larger L., "Compact Optoelectronic Microwave Oscillators using Ultra-High Q Whispering Gallery Mode disk-Resonators and Phase Modulation," Optics Express, 18(21), 22358-22363 (2010).

[9] Salzenstein P., Cussey J., Jouvenceau X., Tavernier H., Larger L., Rubiola E. and Sauvage G., "Realization of a Phase Noise Measurement Bench Using Cross Correlation and Double Optical Delay Line," Acta Physica Polonica A, 112(5), 1107-1111 (2007).

[10] Todorov F., Jelinek M., Matejec V., Chomat M., Kubecek V., Berkova D. and Sedlar R., "Preparation and characterization of optical microspheres for refractive-index sensing," Proc. of SPIE, 7716, 7716X (2010). 